\title{
Mouse Models of Machado-Joseph Disease and Other Polyglutamine Spinocerebellar Ataxias
}

\author{
Veronica F. Colomer Gould \\ Department of Psychiatry, Johns Hopkins University School of Medicine, Baltimore, Maryland 21287
}

\begin{abstract}
Summary: Machado-Joseph disease (MJD), also called spinocerebellar ataxia type 3 , is caused by mutant ataxin-3 with a polyglutamine expansion. Although there is no treatment available at present to cure or delay the onset of MJD, mouse models have been generated to facilitate the development of a therapy. In this review, the published reports on mouse models of MJD and other polyglutamine spinocerebellar ataxias are compared.
\end{abstract}

Based on these studies, the following approaches will be discussed as candidate treatments for MJD: 1) interfering with the formation of the mutant ataxin-3 cleavage fragment and possibly aggregate or inclusions, 2) reducing the disease protein nuclear localization, and 3) decreasing mutant ataxin-3 expression in neurons. Key Words: SCA, MJD, mouse model, ataxin, therapy, cleavage fragment.
Machado-Joseph disease (MJD), also called spinocerebellar ataxia type 3 , is a neurodegenerative disorder characterized by abnormal movement coordination. ${ }^{1}$ The disease is fatal in the most severe cases and is inherited in a dominant manner. ${ }^{1} \mathrm{MJD}$ is one of six spinocerebellar ataxias (SCA1, SCA2, SCA3, SCA6, SCA7, SCA17) that are caused by a protein with a polyglutamine expansion. $^{2,3}$ The polyglutamine protein causing MJD is mutant ataxin-3 with 56-84 consecutive glutamines, in contrast to the 14-37 glutamines in normal ataxin-3.,5 Mutant ataxin-3 has isoforms such as mjd1a that result from alternative splicing and have been detected in brain of MJD patients. ${ }^{4,6}$ Expression of mutant ataxin-3 is widespread, although the neurodegeneration in MJD has been described in particular brain regions such as the cerebellum (dentate nuclei; the Purkinje cells are hardly affected), substantia nigra, and pontine nuclei. ${ }^{1,7,8}$ The mechanisms of selective neurotoxicity are poorly understood. It is controversial whether MJD pathogenesis is associated with the neuronal intranuclear inclusions that contain mutant ataxin-3. ${ }^{9-11}$ Neurotoxicity associated with the disease is proposed to be related to a critical concentration of a mutant ataxin-3 cleavage fragment in the nucleus of selective neurons. ${ }^{12,13}$

Address correspondence and reprint requests to Veronica F. Colomer Gould, Department of Psychiatry, Johns Hopkins University School of Medicine, Meyer Building, Room 4-158, Baltimore, MD 21287. Email: vcolomer@jhu.edu.
Although there is no treatment available at present to cure or delay the onset of MJD, identification of the mutant ataxin-3 gene has been useful for diagnosis and genetic counseling. Major technical obstacles still need to be overcome before gene therapy can be used to cure MJD. In the meantime, MJD patients can benefit from symptomatic treatments ${ }^{14}$ and possibly from therapeutic approaches based on exercise and diets that have been successful in patients with other neurodegenerative diseases. $^{15}$

Identification of the mutant ataxin-3 gene has made possible the development of cell and animal models for use in studying the mechanisms of pathogenesis of MJD. ${ }^{12}$ Cell models are easier to manipulate, but they do not recapitulate all the events that take place in the brain. Mice are the preferred animal model because they are small and short-lived and can be generated in relatively large numbers, kept in a controlled environment, and used for invasive procedures. Being mammals, they have important genomic, anatomical, and physiological similarities to humans. The problems encountered in the use of patient brain tissue, such as autolysis caused by long postmortem delays, can be avoided using mouse models.

In this review, I present candidate goals for MJD therapy based on reports on mouse models of several polyglutamine spinocerebellar ataxias. The scope of this review does not extend to reports on cell models of these diseases, brain tissue of the corresponding patients, or to polyglutamine disorders other than spinocerebellar atax- 
TABLE 1. Ataxic Mouse Models of Polyglutamine Spinocerebellar Ataxias Expressing the Complete Disease Protein in Neurons of the Cerebellum

\begin{tabular}{|c|c|c|c|c|c|c|c|}
\hline $\begin{array}{l}\text { SCA } \\
\text { Type }\end{array}$ & $\begin{array}{l}\text { Human Transgene or } \\
\text { Inserted DNA (\#CAG) }\end{array}$ & Promoter* & $\begin{array}{l}\text { Mutant Ataxin } \\
\text { Fragment in } \mathrm{Cb}\end{array}$ & $\begin{array}{c}\text { Mutant } \\
\text { Ataxin } \\
\text { Subcellular } \\
\text { Localization } \\
\text { in } \mathrm{Cb}^{* *}\end{array}$ & $\begin{array}{l}\text { Intranuclear } \\
\text { Inclusions in } \mathrm{Cb} \\
\text { IR for: }\end{array}$ & $\begin{array}{c}\text { Neuro- } \\
\text { degeneration } \\
\text { in } \mathrm{Cb}^{* * *}\end{array}$ & Reference \\
\hline 1 & cDNA (82) & L7 & nd & nd & $\mathrm{U}, \mathrm{C}$ & + & $25,29,30$ \\
\hline 1 & cDNA (82) & L7 conditional & nd & nd & nd & + & 26 \\
\hline 1 & CAG knock-in (154) & Mouse SCA1 & nd & Nuclear & Ataxin $1 \mathrm{C}$ & + & 31 \\
\hline 2 & cDNA & L7 & nd & Cytop & - & + & 32 \\
\hline 3 & YAC-MJD1 (67-84) & MJD1 & nd & Nuclear & Ataxin $3 \mathrm{U}$ & + & 16 \\
\hline 3 & cDNA mjd1a (71) & Prp & + & Nuclear & Ataxin $3(\mathrm{U})$ & nd & 13 \\
\hline 7 & cDNA $(90)$ & L7 & $+\mathrm{IR}$ & Nuclear & Ataxin $7 \mathrm{U}, \mathrm{C}$ & + & 19 \\
\hline 7 & cDNA (128) & PDGF-B, & $+\mathrm{IR}$ & Nuclear & Ataxin $7 \mathrm{U}, \mathrm{C}, \mathrm{T}$ & nd & 20 \\
\hline 7 & cDNA (92) & Prp & + Not brain specific & Nuclear & Ataxin $7, \mathrm{C}$ & + & 33 \\
\hline 7 & CAG knock-in (266) & Mouse SCA7 & nd & Nuclear & nd & + & 34 \\
\hline
\end{tabular}

*, L7 is a Purkinje specific promoter; the other promoters drive expression throughout the brain although with Prp driven expression is lower in Purkinje cells. **, Subcellular localization at late stages of the disease. ***, The cerebellar neurons could be dysfunctional even if no evidence of degeneration was detected because the mice were ataxic (as determined by failure to remain on an accelerating rod and/or abnormal gait). $\mathrm{Cb}=$ cerebellar neurons or homogenates; nd = not determined or not detected; IR = immunoreactive, or determined by immunohistochemistry; ( ) = unpublished; $\mathrm{U}=$ ubiquitin or proteasome components; $\mathrm{C}=$ chaperones; $\mathrm{T}=$ transcription factors.

ias. The mouse models I compare often differ in terms of the promoters used to drive transgene expression and the tests used for behavioral analyses. However, all of the models I discuss have included transgene expression in the cerebellum and evaluation of movement coordination. Therefore, I have focused on these two aspects in my comparison of the various models.

\section{DECREASING THE FORMATION OF THE MUTANT ATAXIN-3 CLEAVAGE FRAGMENT}

Three different transgenic mouse models of MJD have been generated. In the first, expression of a portion of the mutant ataxin-3 isoform mjd1a in Purkinje cells (neurons poorly affected in MJD) led to neurodegeneration and severe ataxic behavior. ${ }^{12}$ In contrast, expression of fulllength mutant ataxin- 3 mjd1a in these neurons was associated with normal behavior and no reported pathology. ${ }^{12}$ On the basis of these results, it was proposed that neurotoxicity in MJD is produced by a cleavage fragment of mutant ataxin-3 and that the neuron-specific proteolytic enzyme involved could serve as a target for therapy. ${ }^{12}$

In the second mouse model, the entire human MJD1 gene in a yeast artificial chromosome was used, and therefore transgene expression was widespread. ${ }^{16}$ The cleavage fragment was not detected, even though cerebellar ataxia and neurodegeneration were observed. ${ }^{16}$ These findings suggested that either the cleavage fragment hypothesis was wrong, or the level of transgene expression in these mice was not high enough to permit detection of the fragment.

In the third mouse model, the transgenic mice ex- pressed mutant ataxin-3 mjd1a under the control of the mouse prion promoter, which drives expression at high levels and throughout the brain (except in Purkinje cells). ${ }^{13}$ Mutant ataxin-3 and its putative cleavage fragment were enriched in nuclear fractions of brain homogenates from these transgenic mice. ${ }^{13}$ The fragment was abundant in the ataxic transgenic mice and scarce in the mice with lower levels of mutant ataxin-3 expression and a normal behavior. Normal ataxin-3 and its putative cleavage fragment were enriched in the cytoplasmic fraction (my unpublished data). The mutant ataxin-3 cleavage fragment was not detected in testicular cells, suggesting that it is brain specific (my unpublished data) and was more abundant in at least one brain region that is severely affected in MJD (the cerebellum), suggesting that toxicity occurred above a critical nuclear concentration. ${ }^{13}$ Thus, decreasing the concentration of the cleavage fragment below a critical level in brain cells could be a goal for MJD treatment. As a means of reaching this goal, the corresponding proteolytic enzyme needs to be identified and used as a target for therapy. Such an approach has been used for other neurodegenerative disorders, including Alzheimer's ${ }^{17}$ and Huntington's diseases. ${ }^{18}$ The brain-specific cleavage fragment hypothesis may not apply to all polyglutamine spinocerebellar ataxias (Table 1), unless technical problems have interfered with its detection.

\section{DECREASING THE NUCLEAR LOCALIZATION OF MUTANT ATAXIN-3}

Except for SCA2, the disease protein is enriched in the nucleus of cerebellar neurons in all SCA mouse models 
(Table 1). A progressive nuclear localization has been reported for SCA7 mice ${ }^{19,20}$ but remains to be established in all the other mouse models of polyglutamine SCAs. The relevance of nuclear localization to pathogenesis has been confirmed for SCA1: when the disease protein for SCA1 lacked a nuclear localization signal, it did not produce an abnormal phenotype in transgenic mice. ${ }^{21}$ Attempting to reduce the nuclear localization of mutant ataxin-3 will first require a further understanding of the mechanism involved. So far, we know that the polyglutamine expansion is involved because normal ataxin-3 is enriched in the cytoplasm of neurons in transgenic mice. ${ }^{13,16}$

\section{DECREASING THE AGgREGATION OF MUTANT ATAXIN-3 AND CONSEQUENT FORMATION OF INTRANUCLEAR INCLUSIONS}

All SCA mice, again except those with SCA2, have intranuclear inclusions in cerebellar neurons (Table 1). These inclusions show immunoreactivity with antibodies recognizing the corresponding disease proteins and with antibodies specific for other cellular components, such as ubiquitin-proteasome system components, chaperones, and transcription factors (Table 1). Data obtained using MJD transgenic mice suggest that an abundant aggregate and larger inclusions in the nucleus of neurons are correlated with pathogenesis. ${ }^{13}$ Thus, decreasing aggregation and the consequent formation of intranuclear inclusions would appear to be beneficial in MJD. This approach could be attempted using chaperones such as heat shock protein (HSP) 70. Overexpression of the HSP70 heat shock protein has been found to reduce pathology and motor dysfunction in SCA1 transgenic mice. $^{22}$

In SCA1, the disease protein lacking a self-association domain and therefore existing in a permanently nonaggregated (soluble) form has been shown to be toxic in transgenic mice. ${ }^{21}$ Furthermore, SCA1 transgenic mice cross-bred with mice deficient in E6-AP ubiquitin protein ligase (which is involved in proteasome-dependent protein degradation) did not form nuclear inclusions, yet exhibited cerebellar neurodegeneration. ${ }^{23}$ Taken together, these observations suggest that the soluble disease protein is the toxic form and that aggregation and inclusions do not cause pathogenesis. More recent findings suggest, in fact, that the intranuclear inclusions play a protective role and that the ubiquitin-proteasome system is not severely impaired in SCA7 mice. ${ }^{24}$ Thus, similar studies for MJD are needed to determine whether decreasing aggregation and formation of inclusions would actually be a goal for therapy.

\section{DECREASING THE LEVEL OF MUTANT ATAXIN-3 EXPRESSION IN THE BRAIN}

Transgenic mice with low levels of mutant ataxin-3 (Q71 heterozygotes) showed normal behavior and a mild or no pathology. ${ }^{13}$ Likewise, transgenic mice expressing low levels of the SCA1 disease protein exhibited normal behavior and mild or no pathology. ${ }^{25}$ More importantly, in conditional SCA1 mice, the abnormalities caused by the disease protein could be reversed by turning off transgene expression at an early stage of the disorder. ${ }^{26}$ Therefore, decreasing the expression of mutant ataxin-3 may be a realistic goal for MJD therapy. An RNA interference approach can repress transgene expression in SCA1 mice and has been shown to be therapeutic. ${ }^{27}$ RNA interference targeted to mutant ataxin-3 expression has been tested in a cell mode ${ }^{28}$ and could be attempted in a MJD mouse model.

\section{CONCLUSIONS}

The reports on mouse models of different polyglutamine spinocerebellar ataxias suggest several targets for therapy of MJD. These include the proteolytic enzyme that generates the toxic cleavage fragment, and the cellular components involved in mutant ataxin-3 expression, nuclear localization, and formation of the aggregates and inclusions.

\section{REFERENCES}

1. Sudarsky L, Coutinho P. Machado-Joseph disease. Clin Neurosci 3:17-22, 1995.

2. Zoghbi HY, Orr H T. Glutamine repeats and neurodegeneration. Annu Rev Neurosci 23:217-247, 2000.

3. Nakamura K, Jeong S Y, Uchihara T, Anno M, Nagashima K, Nagashima T, et al. SCA17, a novel autosomal dominant cerebellar ataxia caused by an expanded polyglutamine in TATA-binding protein. Hum Mol Genet 10:1441-1448, 2001.

4. Kawaguchi Y, Okamoto T, Taniwaki M, Aizawa M, Inoue M, Katayama S, et al. CAG expansions in a novel gene for MachadoJoseph disease at chromosome 14q32.1. Nat Genet 8:221-228, 1994.

5. Takiyama Y, Sakoe K, Nakano I, Nishizawa M. Machado-Joseph disease: cerebellar ataxia and autonomic dysfunction in a patient with the shortest known expanded allele (56 CAG repeat units) of the MJD1 gene. Neurology 49:604-606, 1997.

6. Ichikawa Y, Goto J, Hattori M, Toyoda A, Ishii K, Jeong SY, et al. The genomic structure and expression of MJD, the MachadoJoseph disease gene. J Hum Genet 46:413-422, 2001.

7. Nishiyama K, Murayama S, Goto J, Watanabe M, Hashida H, Katayama S, et al. Regional and cellular expression of the Machado-Joseph disease gene in brains of normal and affected individuals. Ann Neurol 40:776-781, 1996.

8. Paulson HL, Das SS, Crino PB, Perez MK, Patel SC, Gotsdiner D, et al. Machado-Joseph disease gene product is a cytoplasmic protein widely expressed in brain. Ann Neurol 41:453-462, 1997.

9. Paulson HL, Perez MK, Trottier Y, Trojanowski JQ, Subramony $\mathrm{SH}$, Das SS, et al. Intranuclear inclusions of expanded polyglutamine protein in spinocerebellar ataxia type 3. Neuron 19:333344, 1997.

10. Schmidt T, Landwehrmeyer GB, Schmitt I, Trottier Y, Auburger $\mathrm{G}$, Laccone F, et al. An isoform of ataxin-3 accumulates in the nucleus of neuronal cells in affected brain regions of SCA3 patients. Brain Pathol 8:669-679, 1998. 
11. Yamada M, Hayashi S, Tsuji S, Takahashi H. Involvement of the cerebral cortex and autonomic ganglia in Machado- Joseph disease. Acta Neuropathol (Berl) 101:140-144, 2001.

12. Ikeda H, Yamaguchi M, Sugai S, Aze Y, Narumiya S, Kakizuka A. Expanded polyglutamine in the Machado-Joseph disease protein induces cell death in vitro and in vivo. Nat Genet 13:196-202, 1996.

13. Goti D, Katzen SM, Mez J, Kurtis N, Kiluk J, Ben-Haïem L, et al. A mutant ataxin-3 putative-cleavage fragment in brain of Machado-Joseph disease patients and transgenic mice is cytotoxic above a critical concentration. J Neurosci 24:10266-10279, 2004.

14. Ogawa M. Pharmacological treatments of cerebellar ataxia. Cerebellum 3:107-111, 2004

15. Mattson MP, Chan SL, Duan W. Modification of brain aging and neurodegenerative disorders by genes, diet, and behavior. Physiol Rev 82:637-672, 2002.

16. Cemal CK, Carroll CJ, Lawrence L, Lowrie MB, Ruddle P, AlMahdawi S, et al. YAC transgenic mice carrying pathological alleles of the MJD1 locus exhibit a mild and slowly progressive cerebellar deficit. Hum Mol Genet 11:1075-1094, 2002.

17. Citron M. $\beta$-Secretase inhibition for the treatment of Alzheimer's disease - promise and challenge. Trends Pharmacol Sci 25:92-97, 2004.

18. Ona VO, Li M, Vonsattel JP, Andrews LJ, Khan SQ, Chung WM, et al. Inhibition of caspase-1 slows disease progression in a mouse model of Huntington's disease. Nature 399:263-267, 1999.

19. Yvert G, Lindenberg KS, Picaud S, Landwehrmeyer GB, Sahel JA, Mandel JL. Expanded polyglutamines induce neurodegeneration and trans-neuronal alterations in cerebellum and retina of SCA7 transgenic mice. Hum Mol Genet 9:2491-2506, 2000.

20. Yvert G, Lindenberg K S, Devys D, Helmlinger D, Landwehrmeyer GB, Mandel JL. SCA7 mouse models show selective stabilization of mutant ataxin-7 and similar cellular responses in different neuronal cell types. Hum Mol Genet 10:1679-1692, 2001.

21. Klement IA, Skinner PJ, Kaytor MD, Yi H, Hersch SM, Clark HB, et al. Ataxin-1 nuclear localization and aggregation: role in polyglutamine-induced disease in SCA1 transgenic mice. Cell 95:4153, 1998.

22. Cummings CJ, Sun Y, Opal P, Antalffy B, Mestril R, Orr HT, et al. Over-expression of inducible HSP70 chaperone suppresses neuropathology and improves motor function in SCA1 mice. Hum Mol Genet 10:1511-1518, 2001.

23. Cummings CJ, Reinstein E, Sun Y, Antalffy B, Jiang Y, Ciechanover A, et al. Mutation of the E6-AP ubiquitin ligase reduces nuclear inclusion frequency while accelerating polyglutamine-induced pathology in SCA1 mice. Neuron 24:879-892, 1999.

24. Bowman AB, Yoo SY, Dantuma NP, Zoghbi HY. Neuronal dysfunction in a polyglutamine disease model occurs in the absence of ubiquitin-proteasome system impairment and inversely correlates with the degree of nuclear inclusion formation. Hum Mol Genet 14:679-691, 2005

25. Burright EN, Clark HB, Servadio A, Matilla T, Feddersen RM, Yunis WS, et al. SCA1 transgenic mice: a model for neurodegeneration caused by an expanded CAG trinucleotide repeat. Cell 82:937-948, 1995.

26. Zu T, Duvick LA, Kaytor MD, Berlinger MS, Zoghbi HY, Clark $\mathrm{HB}$, et al. Recovery from polyglutamine-induced neurodegeneration in conditional SCA1 transgenic mice. J Neurosci 24:88538861, 2004.

27. Xia H, Mao Q, Eliason SL, Harper SQ, Martins IH, Orr HT, et al. RNAi suppresses polyglutamine-induced neurodegeneration in a model of spinocerebellar ataxia. Nat Med 10:816-820, 2004.

28. Miller VM, Xia H, Marrs GL, Gouvion CM, Lee G, Davidson BL, et al. Allele-specific silencing of dominant disease genes. Proc Natl Acad Sci USA 100:7195-7200, 2003.

29. Clark H B, Burright E N, Yunis W S, Larson S, Wilcox C, Hartman B, et al. Purkinje cell expression of a mutant allele of SCA1 in transgenic mice leads to disparate effects on motor behaviors, followed by a progressive cerebellar dysfunction and histological alterations. J Neurosci 17:7385-7395, 1997.

30. Cummings CJ, Mancini MA, Antalffy B, DeFranco DB, Orr HT, Zoghbi HY. Chaperone suppression of aggregation and altered subcellular proteasome localization imply protein misfolding in SCA1. Nat Genet 19:148-154, 1998.

31. Watase K, Weeber EJ, Xu B, Antalffy B, Yuva-Paylor L, Hashimoto $\mathrm{K}$, et al. A long CAG repeat in the mouse Scal locus replicates SCA1 features and reveals the impact of protein solubility on selective neurodegeneration. Neuron 34:905-919, 2002.

32. Huynh DP, Figueroa K, Hoang N, Pulst SM. Nuclear localization or inclusion body formation of ataxin-2 are not necessary for SCA2 pathogenesis in mouse or human. Nat Genet 26:44-50, 2000.

33. Garden GA, Libby RT, Fu YH, Kinoshita Y, Huang J, Possin DE, et al. Polyglutamine-expanded ataxin-7 promotes non-cell-autonomous purkinje cell degeneration and displays proteolytic cleavage in ataxic transgenic mice. $J$ Neurosci 22:4897-4905, 2002.

34. Yoo SY, Pennesi ME, Weeber EJ, Xu B, Atkinson R, Chen S, et al. SCA7 knockin mice model human SCA7 and reveal gradual accumulation of mutant ataxin-7 in neurons and abnormalities in short-term plasticity. Neuron 37:383-401, 2003. 